\title{
WOULD YOU LIKE TO BE A PREMIUM CUSTOMER? A RESEARCH ON THE FACTORS RELATED TO THE INTENTION TO PAY FOR A PREMIUM MUSIC SERVICE
}

\author{
DOI: 10.17261/Pressacademia.2020.1196 \\ JMML- V.7-ISS.1-2020(4)-p.42-52
}

Ibrahim Kircova ${ }^{1}$, Pinar Baydogan Turkay², Sirin Gizem Kose ${ }^{3}$

${ }^{1}$ Yıldız Technical University, Business Administration Department, Istanbul, Turkey. kircova@yildiz.edu.tr, ORCID: 0000-0003-2381-5459

${ }^{2}$ Piri Reis University, International Business and Trade Department, Istanbul, Turkey. pbaydogan@pirireis.edu.tr, ORCID: 0000-0001-7145-2432

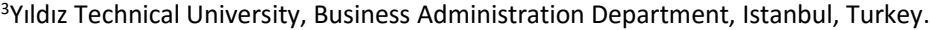
siringizemkose@gmail.com, ORCID: 0000-0002-5604-8148

Date Received: December 9, 2019

Date Accepted: March 18, 2020

To cite this document

Kircova, I., Turkay, P.B., Kose, S.G. (2020), Would you like to be a premium customer? a research on the factors related to the intention to pay for a premium music service. Journal of Management, Marketing and Logistics (JMML), V.7(1), p.42-52.

Permemant link to this document: http://doi.org/10.17261/Pressacademia.2020.1196

Copyright: Published by PressAcademia and limited licenced re-use rights only.

\section{ABSTRACT}

Purpose- Freemium business model offers the customers a limited or unlimited product/service experience. Although the Freemium business model seems to be funded by the advertisement income, the main expectation from the model is to convert users to premium customers for increasing profit margin. In terms of this, the dynamics behind the conversion process of the user to premium customer have been researched in the study.

Methodology- The data were collected from 240 people by online survey method. Hypotheses were tested using Partial Least Squares Structural Equation Modeling (PLS-SEM).

Findings- Results indicate that when perceived value of premium version is higher, attitude towards premium version becomes positive. Also, as the perceived value of premium version increases, attitude towards free version gets negative. Another result states that when the level of personal innovativeness increases, social influence related to premium version also increases.

Conclusion- Attitude towards free version and attitude towards premium version are both related to intention to pay, however, attitude towards premium version has a stronger effect on intention to pay when compared to attitude towards free version. The key point is to balance the benefits package of free and premium versions.

Keywords: Freemium, premium, perceived value, social influence, personal innovativeness.

JEL Codes: M30, M31, L80

\section{INTRODUCTION}

The Freemium business models emerged in the 1980s when software companies started to offer free versions that provided limited features. Nowadays the freemium model is also approached as a pricing and marketing strategy. Freemium has been primarily conceptualized by Wilson (2006) and became one of the most characteristic business models of Web 2.0.

Psychological studies prove that individuals associate the price with the cost, no matter how small the cost is (Anderson, 2009). An individual may spend hours to search for the best price and product, however, the amount an individual saves does not comprise the time cost spent on information search and deciding. When something becomes free, individuals generally tend to ignore the cost. Freemium is an appealing choice to customers since it is a cost-free way of trying a new service. A customer can easily upgrade to special features by paying if he/she is satisfied. While the free version that provides limited features targets a 
large user base and is funded by advertisements, the fundamental aim of Freemium is to gain profit from paid customers by creating user conversion. This conversation rate is the key point of success for companies that use Freemium business models. Finding balance between premium and free version is crucial for achieving conversion (Haruvy and Prasad, 1998; Faugère and Tayi, 2007; Kumar, 2014). A weak free version proposal that is unable to create a large user database and a premium version which does not ensure payment would have a high chance of failure as a model.

Most of the online service providers find the Freemium business model appealing because of creating high volume user traffic without requiring heavy promotion investments. Therefore importance of using this business model has increased both academically and practically. However, there are only limited studies focusing on the Freemium concept. This study intends to explain the factors related to the intention to pay for the paid version by focusing on a music content provider, Spotify, which offers both free and premium versions to its users.

\section{LITERATURE REVIEW}

The model of the study is builded on the theory of reasoned action (Fishbein, 1967), which utilizes subjective norm and attitude to predict behavioral intention. In order to explain the intention to pay for premium offer, the study extended the theory of reasoned action with perceived value and personal innovativeness variables. The literature and related hypotheses are given in the next sections.

\subsection{Personal Innovativeness}

Steenkamp et al. (1999) define personal innovativeness as "tendency to try new products or brands instead of insisting on the previous choices" whereas Agarwal and Prasad (1998) define the concept as "willingness to try novel information technology". Personal innovativeness also reflects the speed of innovation adaptation (Flynn and Goldsmith, 1993). Some researchers approach the concept as a personality trait and claim that personal innovativeness is the determinant of new product adaptation (Citrin et al., 2000) and reflects the willingness to experience innovations (Lin and Filieri, 2015). Measuring innovativeness varies according to the different definitions of innovativeness (Eryiğit and Kavak, 2011). Lu et al. (2005), presented the strong causal relationship among personal innovativeness, social influence and perceptual beliefs in their study. Jones et al. (2002) suggest that personal innovativeness explain technology usage behavior. O'Cass and Fenech (2003) specify that internet users who are highly innovative have high probability to have positive attitudes towards new technologies. Alan et al. (2019) found that personal innovativeness has a moderating effect on the relationship among consumer trust and behavioral intention. Those studies put forward that personal innovativeness demonstrates individuals' innovation adaptation level compared to their social environment, therefore it is expected that individuals who have the tendency to be an early adopter of innovations also affect the others. Akdogan et al. (2018) found that highly innovative consumers may pay a higher price for novel products since they have low price sensitivity. All things considered, the following hypotheses are suggested.

H1: Personal innovativeness is positively related to social influence.

$\mathrm{H} 2$ : Personal innovativeness is positively related to attitude towards the free version.

H3. Personal innovativeness is positively related to attitude towards premium version.

\subsection{Social Influence}

The social influence is described as the psychological situation, subjective feelings, motivations or emotions, beliefs, values or change in behaviors that is the consequence of other individuals' real or imagined presence or actions (Latané, 1981). According to Burnkrant and Cousineau (1975), individuals use others' product evaluations as an information source about products. LópezNicolás et al. (2008) indicated that reference groups affect individuals' behavioral intentions. Phau and Teah (2009) support the direct effect of social factors on behavioral intention while Kulviwat et al. (2009) present findings on the mediator effect of social factors on the relationship among consumer attitudes and behavioral intention. Information about a product's quality shared by others directly affects consumers' evaluation (Cohen and Golden, 1972). López-Nicolás et al. (2008) proved that attitudes are affected by information provided by society. In this vein, it is hypothesized that,

H4: Social influence is positively related to perceived value of premium version. 


\subsection{Perceived Value}

Perceived value has not been clearly defined because of its subjectivity (Khalifa, 2004). The concept of perceived value is vague, and it is related to what the customer perceived and gains (Woodall, 2003). Zeithaml's (1988) definition of perceived value is "the consumer's overall assessment of the utility of a product based on perceptions of what is received and what is given". On the other hand, Patterson and Spreng (1997) claim that value is the exchange of benefits and sacrifices that are perceived by the consumer. Woodruff (1997) explained the concept as the evaluation of products, attributes, and attribute performances. Increasing perceived value is also considered a way of creating competitive advantage (Haghkhah et al., 2020).

In line with those definitions, perceived value is higher when the desired benefits outweigh the costs. Some researchers address perceived value as a single dimension concept (Chen and Chen, 2010, Yang and Peterson, 2004, Tam, 2004; Steenkamp and Geyskens, 2006; Hu et al., 2009) while some address the subject as a multidimensional concept (Sweeney and Soutar, 2001; Sanchez et al., 2006, Heinonen, 2004; Petrick, 2002; Basaran and Aksoy, 2017). This study measures perceived value as a single dimension. Poushneh and Vasquez-Parraga (2019) found that emotional and functional value affect customers' upgrade intentions. Hsu and Lin (2015) put forward that value-for-money was affects a user's intention to purchase paid apps. In the light of these studies, customers are expected to develop reactions as a result of perceived value. Therefore the following hypotheses are suggested.

H5: Perceived value of premium version is negatively related to attitude towards free version.

H6: Perceived value of free version is positively related to attitude towards premium version.

\subsection{Freemium and Premium Service}

The development of the internet and proliferation of computers have brought new products and services to the market and also changed consumers' expectations (Pazvant and Faiz, 2018). One of the novel business models appeared with the improvement in the information technologies is Freemium. The literature on the Freemium business model mostly focused on the intention to convert to premium, namely, intention to pay for the premium version. Wang and Chin (2011) found that there is a positive relationship among the number of premium users that the Freemium users interact and the intention to convert to a premium version. Oestreicher-Singer and Zalmanson (2013) proved that users' engagement rate and willingness to pay for premium services are related, besides, more active users decide more quickly to be a premium after they become a user. Wagner et al. (2014) found that companies are providing Freemium services as a way to increase the chance of user conversion by bringing an intense fit between their free and premium versions. Koch and Benlian (2017) investigated the conversion probability of two different Freemium strategies. Their study found that users who started using Premium first have higher tendencies to convert to premium version compared to users who started using free first. In addition, this effect is strengthened if the functionality of premium and free versions is similar. Voigt and Hinz (2016) suggest that when a user converts to a customer who makes the early payment, users' lifetime value will be high. Hamari et al. (2017) has suggested that quality of service affects intentions to use Freemium services in a positive way and making premium purchases are indirectly related to the service quality. Furthermore, they found that the effect of quality on premium purchases is mediated by the use of Freemium. Since Freemium users usually use free version before the premium version, it is hypothesized that attitude towards free version is related to attitude towards premium version. Furthermore, the theory of reasoned action puts forward that there is a relationship among attitude and behavioral intention (Fishbein, 1967). Therefore, the following hypotheses are suggested.

H7: Attitude towards free version is positively related to attitude towards premium version.

H8: Attitude towards free version is negatively related to intention to pay for the premium version.

H9: Attitude towards premium version is positively related to intention to pay for the premium version. 
Figure 1: Research Model

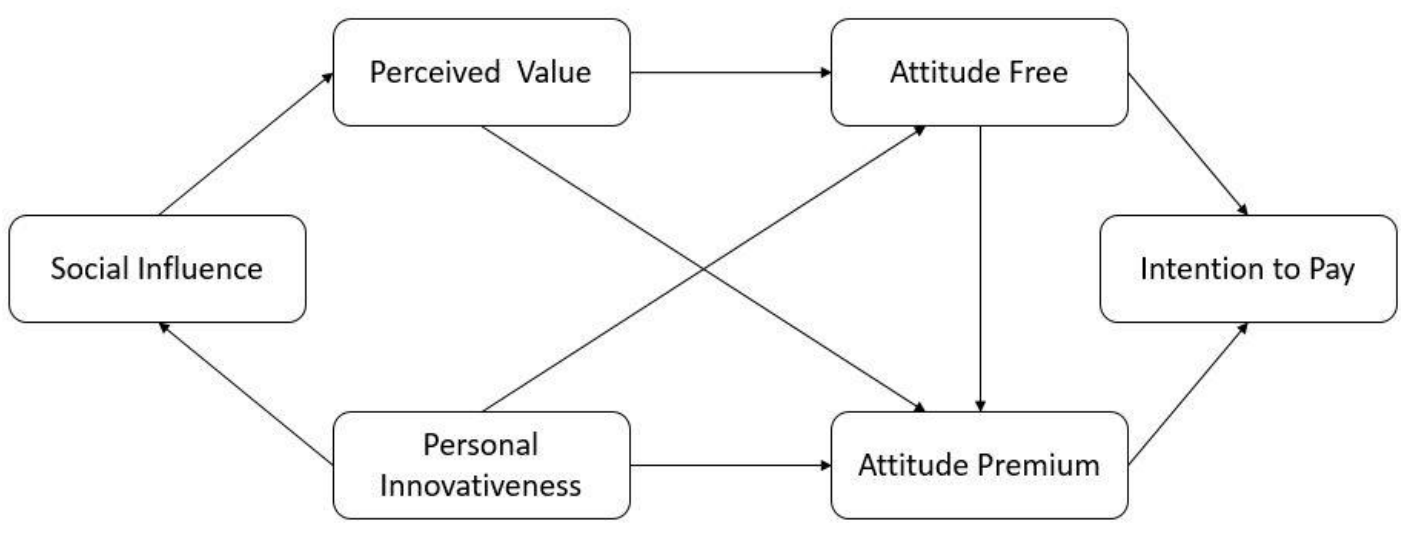

\section{DATA AND METHODOLOGY}

\subsection{Sample and Data Collection}

The population of this study is Spotify users. 289 people answered an online questionnaire during data collection process and all respondents were from Turkey. After eliminating respondents who never used Spotify, a sample size of 240 was obtained. In the first part of the questionnaire, questions regarding the usage of online music services, the usage of free and premium versions of Spotify and payment behavior are included. It was observed that $17.1 \%$ of the respondents were only using the free version of Spotify with limited features, $16.2 \%$ were using the premium version without trying the free version, $66.7 \%$ used the free version first and then subscribed to the premium version. It was also observed that $5 \%$ of the respondents did not pay even though they were using the premium version.

In the second part, there are 26 items and 5-point Likert scales were utilized ranging from 1 (strongly disagree) to 5 (strongly agree). In order to measure attitudes towards free and premium versions of Freemium products and intention to pay, the measures developed by Teng and Laroche (2007) and adapted to Freemium users by Wagner et al. (2014) were used. Attitude towards free version scale consists of 4 items; attitude towards premium version consists of 6 items whereas intention to pay scale consists of 4 items. Furthermore; Kim et al.'s (2013) 3-item scale was used to measure perceived value, Agarwal and Prasad's (1998) 4-item scale was used to measure personal innovativeness, Lu et al.'s (2005) 5-item scale was used to measure social influence.

The third and final part of the questionnaire consists of questions regarding the demographic characteristics of the respondents. $55 \%$ of the respondents were female and $45 \%$ were male. $16.7 \%$ of the participants were aged 25 and under, $61.3 \%$ were between the ages of $26-35,18.3 \%$ were between the ages of $36-45$ and $3.7 \%$ were over the age of 46 . When the education levels of the participants were analyzed, it was observed that $1.2 \%$ were high school graduates, $44.2 \%$ were associate or undergraduate graduates, and $54.6 \%$ had postgraduate degrees.

\subsection{Reliability and Validity Tests}

Structural equation is used by researchers to test causal relationships between latent variables. Structural equation modeling, which is widely used to analyze the cause and effect relationship between latent structures, was born in the marketing literature of the 1980s and was adopted by researchers because of the desire to test all the theories and concepts together (Hair et al., 2011). Data were analyzed with WarpPIs 6.0 program. PLS-SEM, which is accepted as the most advanced approach among variance based structural equation modeling techniques, is widely used in marketing studies (Dijkstra and Henseler, 2015). When compared to covariance-based techniques, PLS-SEM has minimal demands on sample size. Moreover, PLS-SEM is appropriate for complex research models (Chin et al., 2003; Henseler and Chin, 2010) and used by researchers because of it can model latent variables, fix measurement errors and estimate all parameters simultaneously (Dijkstra and Henseler, 2015). 
The study utilized WarpPIs 6.0 to test the measurement and structural model. Scale reliability indicates the internal consistency of the scale and achieved when Cronbach's Alpha (CA) is equal or above 0,7 (Nunnally and Bernstein, 1994). Furthermore, composite reliability (CR) should also be equal to or above 0,7 (Hair et al., 2011). As seen in Table 3, CR and CA values of the study are satisfactory. After reliability analysis, confirmatory factor analysis was applied for validity of the scales. For achieving validity, factor loadings should be equal or above 0,5 (Hair et al., 2014) and be significant at 0,005 level (Fornell and Larckler, 1981; Bagozzi and $\mathrm{Yi}, 1988$ ). Table 3 demonstrates factor loadings, cross-loadings and $\mathrm{p}$ values. According to Table 3 , factor loadings are between 0.545 and 0.944 and significant $(p=0,001)$. Furthermore, AVE values are above 0,5 , proving that there is no problem for convergent validity (Hair et al.2011). Variance Inflation Factor (VIF) values were also checked to avoid multicollinearity problems. Table 3 also demonstrates that VIF values are less than 5 as suggested by Kock (2012), showing that there is no multicollinearity in the measurement model.

In the interest of achieving discriminant validity, Fornell and Larcker criterion is checked. The square root of the AVE for each construct is greater than all of the correlations among the construct and other constructs used in the research as indicated by Fornell Larcker criterion (1981). The values in Table 2 show that Fornell and Larcker criterion is met.

Goodness of fit (Gof) was calculated for the model to test the model fit with the formula developed by Tenenhaus et al. (2005). The values \%10 indicates low, \%25 indicates medium, \%25 indicates high goodness of fit (Wetzels et al., 2009). The calculated value for the model is 0,404 , proving that the research model has high goodness of fit. APC and ARS values should also be significant to achieve the model fit (Kock, 2012). APC and ARS values are also significant as seen in Table 1.

Table 1: Model Fit Indices

\begin{tabular}{|l|l|l|l|}
\hline Index & Results & Acceptance Boundaries & References \\
\hline APC & $0,309^{* *}$ & - & - \\
\hline ARS & $0,2834^{* *}$ & - & - \\
\hline AVIF & 1,055 & Accept if $\leq 5 ;$ ideal if $\leq 3,3$ & (Hair et al., 2011; Kock, 2012) \\
\hline AFVIF & 2,465 & Accept if $\leq 5 ;$ ideal if $\leq 3,3$ & (Hair et al., 2011; Kock, 2012) \\
\hline & & Low $\geq 0,1$, & \\
GoF & 0,404 & $\begin{array}{l}\text { Middle } \geq 0,25, \\
\text { High } \geq 0,36\end{array}$ & $\begin{array}{l}\text { (Wetzels et al.,, 2009; Kock, } \\
\text { 2012) }\end{array}$ \\
\hline $\begin{array}{l}\text { Notes: APC: Average Path Coefficient, ARS: Average } \mathrm{R}^{2}, \text { AVIF: Average Variance Inflation Factor AFVIF: Average Full } \\
\text { Collinearity VIF, Gof: Goodness of Fit. “'***'”' indicates 0,01 level of significance. }\end{array}$ \\
\hline
\end{tabular}

Table 2: Correlation between latent variables and square roots of AVEs

\begin{tabular}{|l|l|l|l|l|l|l|}
\hline & \multicolumn{1}{|c|}{ PERVAL } & \multicolumn{1}{c|}{ SOCINF } & \multicolumn{1}{c|}{ ATTFRE } & \multicolumn{1}{c|}{ ATTPRE } & \multicolumn{1}{c|}{ INTEN } & PI \\
\hline PERVAL & $\mathbf{0 . 8 1 1}$ & & & & & \\
\hline SOCINF & 0.369 & $\mathbf{0 . 7 4 5}$ & & & & \\
\hline ATTFRE & -0.133 & 0.047 & $\mathbf{0 . 8 5 1}$ & & & \\
\hline ATTPRE & 0.616 & 0.197 & -0.126 & $\mathbf{0 . 7 7 3}$ & & \\
\hline INTEN & 0.697 & 0.319 & -0.289 & 0.517 & $\mathbf{0 . 9 1 8}$ & \\
\hline PI & 0.128 & -0.025 & 0.005 & 0.088 & $\mathbf{0 . 7 8 8}$ \\
\hline
\end{tabular}


Table 3: Scale Validation

\begin{tabular}{|c|c|c|c|c|c|c|c|c|c|c|c|c|c|}
\hline & PERVAL & SOCINF & ATTFREE & ATTPREM & INTEN & PIIT & $P$ value & CR & CA & AVE & VIF & $\mathbf{R}^{2}$ & $Q^{2}$ \\
\hline PERVAL1 & $(0.663)$ & -0.201 & -0.085 & -0.160 & -0.480 & 0.017 & $<0.001$ & 0.852 & 0,74 & 0.658 & 4630 & 0.226 & 0.219 \\
\hline PERVAL2 & $(0.694)$ & -0.078 & 0.015 & -0.339 & -0.544 & -0.016 & $<0.001$ & & & & & & \\
\hline PERVAL3 & $(0.765)$ & -0.084 & -0.018 & -0.338 & -0.151 & 0.007 & $<0.001$ & & & & & & \\
\hline SOCINF1 & -0.093 & $(0.852)$ & -0.071 & 0.043 & -0.131 & -0.009 & $<0.001$ & 0.860 & 0,795 & 0.555 & 1180 & 0.039 & 0.040 \\
\hline SOCINF2 & 0.031 & $(0.778)$ & 0.019 & 0.019 & -0.039 & -0.042 & $<0.001$ & & & & & & \\
\hline SOCINF3 & -0.113 & $(0.706)$ & 0.131 & 0.178 & -0.308 & 0.048 & $<0.001$ & & & & & & \\
\hline SOCINF4 & -0.527 & $(0.563)$ & 0.045 & 0.105 & 0.473 & -0.039 & $<0.001$ & & & & & & \\
\hline SOCINF5 & -0.289 & $(0.545)$ & 0.026 & -0.096 & 0.576 & -0.061 & $<0.001$ & & & & & & \\
\hline ATTFREE1 & 0.222 & 0.024 & (0.659) & -0.037 & -0.132 & 0.022 & $<0.001$ & 0.913 & 0,872 & 0.843 & 1210 & 0.091 & 0.083 \\
\hline ATTFREE2 & -0.018 & -0.048 & $(0.824)$ & -0.031 & 0.083 & -0.012 & $<0.001$ & & & & & & \\
\hline ATTFREE3 & 0.268 & -0.080 & $(0.796)$ & -0.041 & -0.036 & 0.013 & $<0.001$ & & & & & & \\
\hline ATTFREE4 & -0.311 & 0.071 & $(0.897)$ & 0.194 & 0.179 & 0.003 & $<0.001$ & & & & & & \\
\hline ATTPRE1 & -0.609 & 0.184 & 0.031 & $(0.553)$ & 0.034 & 0.069 & $<0.001$ & 0.898 & 0,862 & 0.597 & 1926 & 0.598 & 0.577 \\
\hline ATTPRE2 & 0.019 & 0.070 & 0.012 & $(0.662)$ & -0.355 & -0.001 & $<0.001$ & & & & & & \\
\hline ATTPRE3 & -0.420 & 0.148 & -0.126 & (0.699) & -0.090 & 0.015 & $<0.001$ & & & & & & \\
\hline ATTPRE4 & -0.294 & -0.031 & 0.069 & $(0.894)$ & 0.196 & -0.043 & $<0.001$ & & & & & & \\
\hline ATTPRE5 & 0.235 & -0.077 & 0.138 & $(0.732)$ & -0.231 & 0.040 & $<0.001$ & & & & & & \\
\hline ATTPRE6 & -0.225 & 0.016 & 0.097 & (0.779) & 0.286 & -0.054 & $<0.001$ & & & & & & \\
\hline INTEN1 & -0.410 & 0.022 & 0.017 & 0.085 & $(0.944)$ & -0.000 & $<0.001$ & 0.955 & 0.937 & 0.621 & 3551 & 0.462 & 0.443 \\
\hline INTEN2 & -0.159 & 0.008 & 0.065 & 0.031 & $(0.930)$ & -0.005 & $<0.001$ & & & & & & \\
\hline INTEN3 & -0.382 & 0.152 & -0.029 & 0.071 & $(0.722)$ & 0.002 & $<0.001$ & & & & & & \\
\hline INTEN4 & -0.370 & -0.022 & 0.047 & 0.050 & (0.939) & -0.022 & $<0.001$ & & & & & & \\
\hline PIIT1 & -0.246 & 0.073 & -0.106 & 0.055 & 0.091 & $(0.735)$ & $<0.001$ & 0.867 & 0,937 & 0.724 & 1031 & & \\
\hline PIIT2 & 0.028 & -0.121 & -0.179 & -0.026 & -0.143 & (0.591) & $<0.001$ & & & & & & \\
\hline PIIT3 & -0.211 & 0.143 & 0.050 & 0.109 & 0.100 & $(0.644)$ & $<0.001$ & & & & & & \\
\hline PIIT4 & -0.106 & -0.007 & 0.026 & 0.021 & 0.046 & $(0.872)$ & $<0.001$ & & & & & & \\
\hline
\end{tabular}

Lastly, $R^{2}$ and $Q^{2}$ values were calculated to test model fit. $R^{2}$ indicates estimation power of the model and it is valued between 0 and 1. In consumer behavior studies, $R^{2}$ value is accepted high when it is over 0,20 (Hair et al., 2011). Besides, $Q^{2}$ value is expected to be over 0 if the relationships in the model have high estimation power (Weerawardena et al., 2015). $R^{2}$ and $Q^{2}$ values are satisfactory and demonstrated in Table 3. 


\subsection{Path Analysis}

The research hypotheses were tested with WarpPls 6.0 program. The research model is defined as a reflective measurement model. The path analysis is shown in Figure 2. 6 of the 9 hypotheses are accepted at $p=0,01$ significance level. As seen on path analysis, the model explains $\% 46$ of the variance in the intention to pay.

Figure 2: Path Analysis

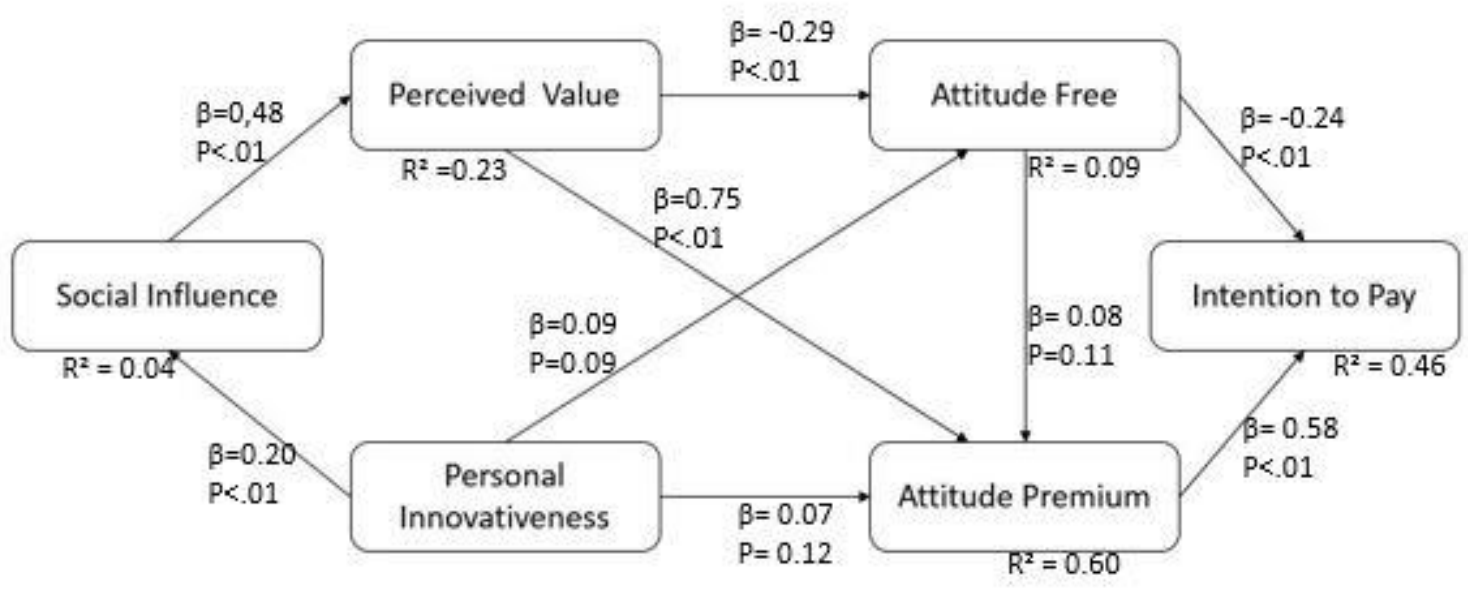

The first hypothesis of the study states that there is a positive relationship among users' personal innovativeness and social influence and the hypothesis is supported $(\beta=0,198, p<0,001)$. The second hypothesis connotes that there is a positive relationship among users' personal innovativeness and attitude towards free version and the hypothesis is rejected $(\beta=0,086, p>0,001)$. The third hypothesis states that users' personal innovativeness is positively related to attitude towards premium version and it is also rejected $(\beta=0.0750, p>0,001)$.

The fourth hypothesis expresses that there is a positive relationship among social influence related to premium version and perceived value of premium version and the hypothesis is supported $(\beta=0,476, p<0,001)$. The fifth and sixth hypotheses of the study express that there is a significant relationship among perceived value of premium version and attitudes towards free and premium versions. Results indicate that there is a negative relationship among perceived value of premium version and attitudes towards free version $(\beta=-0,292, p<0,001)$ whereas there is a positive relationship among perceived value of premium version and attitudes towards premium version $(\beta=0,754, p<0,001)$. Therefore, both of the hypotheses are supported.

The seventh hypothesis of the study states that there is a positive relationship among attitude towards free version and attitude towards premium version and it is rejected $(\beta=-0.077, p>0,001)$. The eighth hypotheses indicate that there is a negative relationship among attitude towards free version and intention to pay and it is supported $(\beta=-0,243, p<0,001)$. Furthermore, the ninth hypothesis which presents that there is a positive relationship among attitude towards premium version and intention to pay is also supported. $(\beta=0,576, p=0,001)$. It can be concluded that attitude towards premium version has strongly related to intention to pay when compared to attitude towards free version.

The findings of the path analysis are summarized in Table 4. 
Table 4: Summary of Findings Related to Path Analysis

\begin{tabular}{|l|l|l|l|l|l|}
\hline Hypothesis & Path Coefficient $(\boldsymbol{\beta})$ & Significance $(\mathbf{P})$ & Std. Error & Effect Size $\left(\mathrm{f}^{2}\right)$ & Result \\
\hline Personal Innovativeness $\rightarrow$ Social Influence & 0.198 & $<0.001$ & 0.062 & 0.039 & Supported \\
\hline Personal Innovativeness $\rightarrow$ Attitude Free & 0.086 & 0.089 & 0.064 & 0.007 & $\begin{array}{l}\text { Not } \\
\text { Supported }\end{array}$ \\
\hline Personal Innovativeness $\rightarrow$ Attitude Premium & 0.075 & 0.120 & 0.064 & 0.007 & Rejected \\
\hline Social Influence $\rightarrow$ Perceived Value & 0.476 & $<0.001$ & 0.059 & 0.226 & Supported \\
\hline Perceived Value $\rightarrow$ Attitude Free & -0.292 & $<0.001$ & 0.061 & 0.085 & Supported \\
\hline Perceived Value $\rightarrow$ Attitude Premium & 0.754 & $<0.001$ & 0.057 & 0.571 & Supported \\
\hline Attitude Free $\rightarrow$ Attitude Premium & -0.077 & 0.114 & 0.064 & 0.020 & $\begin{array}{l}\text { Not } \\
\text { Supported }\end{array}$ \\
\hline Attitude Free $\rightarrow$ Intention to Pay & -0.243 & $<0.001$ & 0.062 & 0.095 & Supported \\
\hline Attitude Premium $\rightarrow$ Intention to Pay & 0.576 & $<0.001$ & 0.058 & 0.367 & Supported \\
\hline
\end{tabular}

\section{CONCLUSION}

The digital world has brought several new features, abilities and needs to consumers and markets. Rapid improvement in technology has changed many industries including the music industry. Freemium based music services have become an important player in the market with digitalization waves. Users' habit of listening to music has been strengthened with the help of music providers and earnings from online music sales have surpassed physical music sales (Pwc, 2019). Freemium business model has increased its importance not only in the music industry, but also in gaming, film, video, social media, and storage services. Therefore, freemium business model concept is noteworthy to investigate.

This research analyzes the relationships between attitude towards free version, attitude towards premium version and intention to pay for Spotify, which is a freemium based music provider. Furthermore, the relationships between social influence related to premium version, perceived value of premium version, personal innovativeness and attitude towards free version and attitude towards premium version is investigated. 6 out of 9 hypotheses are supported $(p=0,01)$ after the analysis. Results indicate that when perceived value of premium version is higher, attitude towards premium version becomes positive $(\beta=0.754, p<0,001)$. As the user enjoys the application and thinks that the benefit of the service is higher than the cost, the user develops more positive attitudes. However, as the perceived value of premium version increases, attitude towards free version becomes negative $(\beta=-$ $0.292, p<0,001)$. It should be underlined that when users have negative attitudes towards free version, their intention to pay increases $(\beta=-0.243, p<0,001)$. This relationship can be explained by the reality that when users are not satisfied with the free version's limited features; they intend to pay more premium version. The key point is to balance the benefit packages of free and premium versions. The thin line between free and premium versions is considered as essential converting freemium users as Kumar (2014) indicated.

Findings also show that as users' attitude towards premium version becomes positive, their intention to pay increases ( $\beta=0,576$, $p<0,001)$. The relationship is expected since it is based on the theories that explain attitude, intention, and behavior (Fishbein and Ajzen, 1977). Another confounding finding is that there is no relationship among attitude towards free version and attitude towards premium version $(\beta=-0.077, p=0,114)$. However, attitude towards free version and attitude towards premium version are both related to intention to pay. According to the results, perceived value of premium version is more important than attitude towards premium version for users. In addition, social influence related to premium price has a positive relationship with perceived value of premium version $(\beta=0.476, p<0,001)$. Individuals perceive the value of premium version higher when their reference group uses or suggests using premium version. Another result reveals that when the level of personal innovativeness increases, social influence related to premium version also increases $(\beta=0.198 ; p<0,001)$. Following this result, it can be inferred that if a services' users are open to innovativeness, premium users can be perceived as more influential. Lastly, there is no relationship among personal innovativeness and attitude towards premium version $(\beta=0.075, p=0,120)$. In addition, personal innovativeness is not related to attitude towards free version $(\beta=0,086, p=0.089)$. It can be said that although personal innovativeness can be used to increase social influence, this variable is not a meaningful trait to change attitudes. 
Although this research has some noteworthy findings in a promising area, it also has some limitations. Firstly, this research has been carried out on Spotify. Future studies can replicate the study on other Freemium based services and include more variables. Secondly, the sample consists of users from only one country, Turkey. Other studies may include a sample from other countries to compare the results. Even with these limitations, this study is expected to shed light on the management and marketing of freemium based services by investigating the essential factors in the process of converting free freemium users to paying premium customers.

\section{REFERENCES}

Agarwal, R., \& Prasad, J. (1998). A conceptual and operational definition of personal innovativeness in the domain of information technology. Information systems research, 9(2), 204-215.

Akdogan, S., Uyar, K., Gullu, K. (2018). Profiles of consumer innovativeness in Turkey. Journal of Management, Marketing and Logistics (JMML), V.5(3), p.236-245.

Alan, A. K., Kabadayi, E. T., \& Bakis, S. (2019). Creating experience in digital music services: the role of personal innovativeness and mobilitycreating experience in digital music services. In Structural Equation Modeling Approaches to E-Service Adoption (pp. 125-147). IGI Global.

Anderson, C. (2009). Free: the future of radical pricing. New York: Random House Business Books.

Bagozzi, R. P., \& Yi, Y. (1988). On the evaluation of structural equation models. Journal Of The Academy Of Marketing Science, 16(1), 74-94.

Basaran, U. and R. Aksoy, (2017). The effect of perceived value on behavioural intentions. Journal of Management, Marketing and Logistics (JMML), V.4, Iss.1, p.1-16

Burnkrant, R. E., \& Cousineau, A. (1975). Informational and normative social influence in buyer behavior. Journal of Consumer research, 2(3), 206215.

Chen, C. F., \& Chen, F. S. (2010). Experience quality, perceived value, satisfaction and behavioral intentions for heritage tourists. Tourism Management, 31(1), 29-35.

Chin, W. W., Marcolin, B. L., \& Newsted, P. R. (2003). A partial least squares latent variable modeling approach for measuring interaction effects: Results from a Monte Carlo simulation study and an electronic-mail emotion/adoption study. Information Systems Research, 14(2), 189-217.

Chin, W. W., \& Newsted, P. R. (1999). Structural equation modeling analysis with small samples using partial least squares. Statistical Strategies For Small Sample Research, 1(1), 307-341.

Citrin, A. V., Sprott, D. E., Silverman, S. N., \& Stem, D. E. (2000). Adoption of Internet shopping: the role of consumer innovativeness. Industrial management \& data systems.

Cohen, J. B., \& Golden, E. (1972). Informational social influence and product evaluation. Journal of Applied Psychology, 56(1), 54.

Dijkstra, T. K., \& Henseler, J. (2015). Consistent partial least squares path modeling. MIS Quarterly, 39(2).

Eryiğit, C., \& Kavak, B. (2011). Tüketici Yenilikçiliğinin Tutumsal Ve Davranişsal Uyumunun İncelenmesi. Hacettepe Üniversitesi İktisadi ve İdari Bilimler Fakültesi Dergisi, 29(2), 95-113.

Faugère, C., \& Tayi, G. K. (2007). Designing free software samples: a game theoretic approach. Information Technology and Management, 8(4), 263-278.

Fishbein, M. (1967). A behavior theory an approach to the relations between beliefs about an object and the attitude toward the object. In M. E. Fishbein, Readings in attitude theory and measurement, Oxford: Wiley.

Flynn, L. R., \& Goldsmith, R. E. (1993). A validation of the Goldsmith and Hofacker innovativeness scale. Educational and Psychological Measurement, 53(4), 1105-1116.

Fornell, C., \& Larcker, D. F. (1981). Evaluating structural equation models with unobservable variables and measurement error. Journal of Marketing Research, 18(1), 39-50.

Haghkhah, A., Rasoolimanesh, S. M., \& Asgari, A. A. (2020). Effects Of Customer Value And Service Quality On Customer Loyalty: Mediation Role Of Trust And Commitment In Business-To-Business Context. Management Research \& Practice, 12(1).

Hair, J. F., Ringle, C. M., \& Sarstedt, M. (2011). PLS-SEM: Indeed a silver bullet. Journal of Marketing theory and Practice, 19(2), $139-152$. 
Hair, J.F., Black, W.C., Babin, B.J. \& Anderson, R.E. (2014). Multivariate Data Analysis. New York, Pearson.

Hamari, J., Hanner, N., \& Koivisto, J. (2017). Service quality explains why people use freemium services but not if they go premium: An empirical study in free-to-play games. International Journal of Information Management, 37(1), 1449-1459.

Haruvy, E., \& Prasad, A. (1998). Optimal product strategies in the presence of network externalities. Information Economics and Policy, 10(4), 489499.

Heinonen, K. (2004). Reconceptualizing customer perceived value: the value of time and place. Managing Service Quality: an international journal.

Henseler, J., \& Chin, W. W. (2010). A comparison of approaches for the analysis of interaction effects between latent variables using partial least squares path modeling. Structural Equation Modeling, 17(1), 82-109.

Hsu, C. L., \& Lin, J. C. C. (2015). What drives purchase intention for paid mobile apps?-An expectation confirmation model with perceived value. Electronic Commerce Research and Applications, 14(1), 46-57.

Hu, H. H., Kandampully, J., \& Juwaheer, T. D. (2009). Relationships and impacts of service quality, perceived value, customer satisfaction, and image: an empirical study. The service Industries Journal, 29(2), 111-125.

Jones, E., Sundaram, S., \& Chin, W. (2002). Factors leading to sales force automation use: A longitudinal analysis. Journal of Personal Selling \& Sales Management, 22(3), 145-156.

Khalifa, A. S. (2004). Customer value: a review of recent literature and an integrative configuration. Management Decision. c. 42 s. 5: $645-666$.

Kim, Y. H., Kim, D. J., \& Wachter, K. (2013). A study of mobile user engagement (MoEN): Engagement motivations, perceived value, satisfaction, and continued engagement intention. Decision Support Systems, 56, 361-370.

Koch, O. F., \& Benlian, A. (2017). The effect of free sampling strategies on freemium conversion rates. Electronic Markets, 27(1), 67-76.

Kock, N. (2012). WarpPLS 5.0 User Manual. Laredo, Texas: ScriptWarp Systems.

Kulviwat, S., Bruner II, G. C., \& Al-Shuridah, O. (2009). The role of social influence on adoption of high tech innovations: The moderating effect of public/private consumption. Journal of Business Research, 62(7), 706-712.

Kumar, V. (2014). Making "Freemium" Work. Harvard Business Review, 27-29.

Latané, B. (1981). The psychology of social impact. American Psychologist, 36(4), 343-356.

Lin, Z., \& Filieri, R. (2015). Airline passengers' continuance intention towards online check-in services: The role of personal innovativeness and subjective knowledge. Transportation Research Part E: Logistics and Transportation Review, 81, 158-168.

López-Nicolás, C., Molina-Castillo, F. J., \& Bouwman, H. (2008). An assessment of advanced mobile services acceptance: Contributions from TAM and diffusion theory models. Information \& Management, 45(6), 359-364.

Lu, J., Yao, J. E., \& Yu, C. S. (2005). Personal innovativeness, social influences and adoption of wireless Internet services via mobile technology. The Journal of Strategic Information Systems, 14(3), 245-268.

Nunnally, J. C., Bernstein, I.H. (1994). Psychometric theory. New York: MCGraw-Hill.

O'cass, A., \& Fenech, T. (2003). Web retailing adoption: exploring the nature of internet users Web retailing behaviour. Journal of Retailing and Consumer services, 10(2), 81-94.

Oestreicher-Singer, G., \& Zalmanson, L. (2013). Content or community? A digital business strategy for content providers in the social age. MIS quarterly, 591-616.

Patterson, P. G., \& Spreng, R. A. (1997). Modelling the relationship between perceived value, satisfaction and repurchase intentions in a businessto-business, services context: an empirical examination. International Journal of service Industry management. Vol. 8 No. 5, pp. 414-434.

Pazvant, E. \& Faiz, E. (2018). Evaluation of the intention of using products with internet of things within the context of technology acceptance model, Journal of Management, Marketing and Logistics (JMML), V.5(1), p.41-54.

Petrick, J. F. (2002). Development of a multi-dimensional scale for measuring the perceived value of a service. Journal of Leisure Research, 34(2), 119-134.

Phau, I., \& Teah, M. (2009). Devil wears (counterfeit) Prada: a study of antecedents and outcomes of attitudes towards counterfeits of luxury brands. Journal of Consumer Marketing, 26(1), 15-27. 
Poushneh, A., \& Vasquez-Parraga, A. Z. (2019). Emotional bonds with technology: the impact of customer readiness on upgrade intention, brand loyalty, and affective commitment through mediation impact of customer value. Journal of Theoretical and Applied Electronic Commerce Research, 14(2), 0-0.

Pwc, (2019, August 20). Perspectives from the Global Entertainment and Media Outlook 2017-2021. Retrieved from https://www.pwc.com/outlook

Sanchez, J., Callarisa, L., Rodriguez, R. M., \& Moliner, M. A. (2006). Perceived value of the purchase of a tourism product. Tourism Management, 27(3), 394-409.

Steenkamp, J. B. E., Ter Hofstede, F., \& Wedel, M. (1999). A cross-national investigation into the individual and national cultural antecedents of consumer innovativeness. Journal of Marketing, 63(2), 55-69.

Steenkamp, J. B. E., \& Geyskens, I. (2006). How country characteristics affect the perceived value of web sites. Journal of Marketing, 70(3), 136150.

Sweeney, J. C., \& Soutar, G. N. (2001). Consumer perceived value: The development of a multiple item scale. Journal of Retailing, 77(2), $203-220$.

Tam, J. L. (2004). Customer satisfaction, service quality and perceived value: an integrative model. Journal of Marketing Management, 20(7-8), 897-917.

Tenenhaus, M., Vinzi, V. E., Chatelin, Y. M., \& Lauro, C. (2005). PLS path modeling. Computational Statistics \& Data Analysis, 48(1), $159-205$.

Teng, L., \& Laroche, M. (2007). Building and testing models of consumer purchase intention in competitive and multicultural environments. Journal of Business Research, 60(3), 260-268.

Voigt, S., \& Hinz, O. (2016). Making digital freemium business models a success: Predicting customers' lifetime value via initial purchase information. Business \& Information Systems Engineering, 58(2), 107-118.

Wagner, T. M., Benlian, A., \& Hess, T. (2014). Converting freemium customers from free to premium - the role of the perceived premium fit in the case of music as a service. Electronic Markets, 24(4), 259-268.

Wang, H., \& Chin, A. (2011, March). Social influence on being a pay user in freemium-based social networks. In 2011 IEEE International Conference on Advanced Information Networking and Applications (pp. 526-533). IEEE.

Weerawardena, J., Mort, G. S., Salunke, S., Knight, G., \& Liesch, P. W. (2015). The role of the market sub-system and the socio-technical sub-system in innovation and firm performance: A dynamic capabilities approach. Journal of the Academy of Marketing Science, 43(2), 221-239.

Wetzels, M., Odekerken-Schröder, G., \& Van Oppen, C. (2009). Using PLS path modeling for assessing hierarchical construct models: Guidelines and empirical illustration. MIS quarterly, 177-195.

Wilson, F. (2006). My Favorite Business Model. Retrieved from https://avc.com/2006/03/the_freemium_bu

Woodall, T. (2003). Conceptualising 'value for the customer': an attributional, structural and dispositional analysis. Academy of Marketing Science Review, 12(1), 1-42.

Woodruff, R. B. (1997). Customer value: the next source for competitive advantage. Journal of The Academy of Marketing Science, $25(2), 139$.

Yang, Z., \& Peterson, R. T. (2004). Customer perceived value, satisfaction, and loyalty: The role of switching costs. Psychology \& Marketing, 21(10), 799-822.

Zeithaml, V. A. (1988). Consumer perceptions of price, quality, and value: a means-end model and synthesis of evidence. Journal of Marketing, $52(3), 2-22$. 